\title{
Patient decision aids for urinary diversion after radical cystectomy: their potential and pitfalls
}

\author{
Eva Browne ${ }^{1}$, Jack Whooley ${ }^{1}$, Jianwei Wang ${ }^{2}$, Niall F. Davis ${ }^{1,3}$ \\ ${ }^{1}$ Department of Urology, Beaumont Hospital, Dublin, Ireland; ${ }^{2}$ Department of Urology, Beijing Jishuitan Hospital, The Fourth Medical College of \\ Peking University, Beijing 100096, China; ${ }^{3}$ Royal College of Surgeons in Ireland (RCSI), Dublin, Ireland \\ Correspondence to: Niall F. Davis. Department of Urology, Beaumont Hospital, Dublin, Ireland. Email: nialldavis@beaumont.ie. \\ Provenance: This is an invited article commissioned by Section Editor Xiao Li (Department of Urology, Jiangsu Cancer Hospital \& Jiangsu Institute \\ of Cancer Research \& Nanjing Medical University Affiliated Cancer Hospital, Nanjing, China). \\ Comment on: McAlpine K, Lavallée LT, Stacey D, et al. Development and Acceptability Testing of a Patient Decision Aid for Urinary Diversion with \\ Radical Cystectomy. J Urol 2019. [Epub ahead of print].
}

Submitted Aug 07, 2019. Accepted for publication Aug 11, 2019.

doi: $10.21037 /$ tau.2019.08.17

View this article at: http://dx.doi.org/10.21037/tau.2019.08.17

We read, with interest, the manuscript by McAlpine $e t$ al. outlining their development of patient decision aids (PtDA) to assist patients undergoing cystectomy in deciding which type of urinary diversion to have performed. The two main types of urinary diversion dealt with by McAlpine et al. are ileal conduit diversion and orthotopic neobladder formation as these are the two most commonly performed urinary diversions $(1,2)$. Both techniques have significant implications for the patient's future quality of life and some consequences may not be acceptable for some patients (1). The ileal conduit is well recognised as the most simple type of urinary diversion but may be unsatisfactory to some patients due to the presence of an abdominal stoma (3). Orthotopic neobladders are often felt to have better results in terms of a patient's body image, given it's closer mimicking of the position of the bladder, but have associated issues with incontinence and potentially the need to self-catheterise which may be unacceptable to some patients $(3,4)$. These very different aspects of each urinary diversion highlight the need to thoroughly counsel patients pre-operatively, as recommended by the World Health Organisation Consensus Conference on Bladder Cancer (5). Patients must weigh the advantages and disadvantages of either option of urinary diversion in order to come to a decision. The development of a PtDA by McAlpine et al. is therefore an incredibly useful tool for both patients and clinicians for use in shared decision making.

This PtDA developed by McAlpine et al. explains what is entailed in either an orthotopic neobladder, referred to as an "internal bladder replacement" and an ileal conduit, referred to as an "abdominal stoma". It discusses urinary incontinence, urinary retention, nocturnal enuresis the possible complications of a neobladder and parastomal hernia and stoma stenosis as possible complications of an ileal conduit. The PtDA then attempts to determine a patient's preference towards each of these possible consequences before asking the patient if they feel ready to make a decision. The PtDA also contains a caveat that the situation may change intra-operatively and so options for reconstruction may be limited.

The development of this tool seems to be very robust as the authors adhered to the International Patient Decision Aids Standards (IPDAS) criteria which ensures the development of quality PtDAs with minimal risk of bias (6). The IPDAS criteria comprises of a 74-point checklist for the development of a PtDA encompassing areas of content, development process and effectiveness (6). This PtDA has also been aimed at those with at least a sixth grade reading level which means that the content of this PtDA should be comprehensible to anyone with a reading age of 11 years which means that this PtDA will be suitable to the vast majority of patients undergoing cystectomy (2).

Unfortunately, there is a lack of randomised controlled trials comparing ileal conduits and orthotopic neobladders due to the restrictions on which patients are suitable for either option. These restrictions predominately limit the 
formation of an orthotopic neobladder in patients with an inadequate sphincter mechanism or in those with urethral disease such as transitional cell carcinoma involving the urethra, or stricture disease (7). Therefore, this decision aid may not be applicable across all patient situations as not all patients will be suitable for an orthotopic neobladder as a result of disease, dexterity or anatomy. Ileal conduit is also more often performed than orthotopic neobladder and the option to have an orthotopic neobladder may also not be available due to surgeon skill (8). This decision aid, therefore, may be of use to a much smaller patient cohort than originally intended.

Unfortunately, this publication only describes the results of the alpha testing of this $\mathrm{PtDA}$. Alpha testing was performed with 18 stakeholders (8 academic urologists, 9 patients, 1 advanced practice nurse). The acceptability testing from this group was very high with $94 \%$ (17 of 18 ) agreeing that this would be a useful tool for patients facing a decision on urinary diversion (2). This small group, which we acknowledge was purely used for initial acceptability testing carries a risk of bias given the academic urologists wealth of knowledge on the topic and thus significant understanding of the implications of either urinary diversion. The group of patients selected for testing also carry a risk of bias as they have a much greater level of understanding of either procedure having had either ileal conduit or orthotopic neobladder performed and therefore cannot accurately represent the group of patients who would require use of this tool. We look forward to reading the results of the beta testing of this PtDA which McAlpine et al. report will be prospectively performed.

The length of this PtDA aid is 11 pages. In alpha testing this length is deemed appropriate by $94 \%$ (17 of 18) of stakeholders (2). The PtDA certainly contains a great deal of detail pertinent to a patient's decision on their choice of urinary diversion. It may, however, feel at little overwhelming to have so much information presented in this format given the life-altering nature of this decision, a process that the authors aim to simplify. As such, the information provided in such a decision aid could be simplified. For example, given that the decision aid is for use in choosing between ileal conduit and orthotopic neobladder it may be superfluous to mention the option of continent cutaneous diversion. There also seems to be a slight repetition in information presented as "advantages" and "disadvantages" of either urinary diversion.

The authors recognise their limitations in developing such a decision aid especially given that lack of randomised controlled trials comparing the types of urinary diversion and importantly the lack of patient reported outcomes in either type (2). This is, however, a potentially invaluable tool for urologists in a broader discussion with patients over preferred diversion type. We eagerly await the results of the authors prospective testing in patients preparing to undergo radical cystectomy and urinary diversion.

\section{Acknowledgments}

None.

\section{Footnote}

Conflicts of Interest: The authors have no conflicts of interest to declare.

Ethical Statement: The authors are accountable for all aspects of the work in ensuring that questions related to the accuracy or integrity of any part of the work are appropriately investigated and resolved.

\section{References}

1. Smith JA, Howards SS, Preminger GM, et al. editors. Hinman's atlas of urologic surgery. 4th edition. Philadelphia: Elsevier, 2018.

2. McAlpine K, Lavallée LT, Stacey D, et al. Development and Acceptability Testing of a Patient Decision Aid for Urinary Diversion with Radical Cystectomy. J Urol 2019. [Epub ahead of print].

3. Aboumarzouk OM, Drewa T, Olejniczak P, et al. Laparoscopic radical cystectomy: neobladder or ileal conduit, debate still goes on. Cent European J Urol 2014;67:9-15.

4. Gburek BM, Lieber MM, Blute ML. Comparison of studer ileal neobladder and ileal conduit urinary diversion with respect to perioperative outcome and late complications. J Urol 1998;160:721-3.

5. World Health Organization (WHO) Consensus Conference on Bladder Cancer, Hautmann RE, AbolEnein H, et al. Urinary diversion. Urology 2007;69:17-49.

6. Elwyn G, O'Connor A, Stacey D, et al. Developing a quality criteria framework for patient decision aids: online international Delphi consensus process. BMJ 2006;333:417.

7. Wein AJ, Kavoussi LR, Partin AW, et al. Campbell-Walsh urology. 11th ed. Philadelphia, PA: Elsevier, 2016. 
8. Roghmann F, Becker A, Trinh QD, et al. Updated assessment of neobladder utilization and morbidity according to urinary diversion after radical cystectomy:

Cite this article as: Browne E, Whooley J, Wang J, Davis NF. Patient decision aids for urinary diversion after radical cystectomy: their potential and pitfalls. Transl Androl Urol 2019;8(Suppl 5):S507-S509. doi: 10.21037/tau.2019.08.17
A contemporary US-population-based cohort. Can Urol Assoc J 2013;7:E552-60. 